\title{
Treatment of overweight and obesity in children and youth: a systematic review and meta-analysis
}

\author{
Leslea Peirson PhD, Donna Fitzpatrick-Lewis MSW, Katherine Morrison MD, Rachel Warren MA, \\ Muhammad Usman Ali MD, Parminder Raina $\mathrm{PhD}$
}

\section{Abstract}

Background: Childhood obesity is a public health concern. One-third of North American children and youth are overweight or obese. We reviewed the evidence of behavioural and pharmacological weight-management interventions on body mass index (BMI), BMl z-score and the prevalence of overweight and obesity in children and youth.

Methods: We updated the search of a previous review. We searched 4 databases up to August 2013. We included randomized trials of primary care-relevant behavioural (diet, exercise, lifestyle) and pharmacological (orlistat) interventions for treating overweight and obesity in children and youth aged 2-18 years if 6-month post-baseline data were provided for BMI, BMI z-score or prevalence of overweight and obesity. In addition, we examined secondary health outcomes such as lipid and glucose levels, blood pressure, quality of life and physical fitness. We included any study reporting harms. We performed meta-analyses when possible, and we examined the features of interventions that showed benefits.

Results: Thirty-one studies (29 behavioural, 2 pharmacological and behavioural) were included. Both intervention types showed a significant effect on BMI or BMI Z-score in favour of treatment (behavioural: standardized mean difference [SMD] -0.54, 95\% confidence interval $[\mathrm{Cl}]-0.73$ to -0.36 ; orlistat plus behavioural: SMD $-0.43,95 \% \mathrm{Cl}-0.60$ to -0.25$)$. Studies reported no significant difference between groups in the likelihood of reduced prevalence of overweight or overweight and obesity. Pooled estimates for blood pressure and quality of life showed significant benefits in favour of treatment (systolic blood pressure mean difference [MD] $-3.42,95 \% \mathrm{Cl}-6.65$ to -0.29 ; diastolic blood pressure $\mathrm{MD}-3.39,95 \% \mathrm{Cl}-5.17$ to -1.60 ; quality of life $\mathrm{MD} 2.10,95 \% \mathrm{Cl} 0.60$ to 3.60 ). Gastrointestinal difficulties were more common in youth taking orlistat than in the control group (risk ratio $3.77,95 \% \mathrm{Cl} 2.56$ to 5.55 ). We saw much variability across efficacious interventions.

Interpretation: Low- to moderate-quality evidence suggests behavioural treatments are associated with a medium effect in terms of reduced $\mathrm{BMI}$ or BMI z-score compared with a small effect shown by combined pharmacological-behavioural interventions. Future research should evaluate active weight maintenance interventions in adolescents with longer follow-up and examine the effectiveness of combined pharmacological and behavioural interventions. Registration: PROSPERO no. CRD42012002754

\begin{abstract}
ccording to the World Health Organization, schoolaged children and youth (aged 5-19 years) whose -weight is greater than the 85 th centile are overweight, and those whose weight is above the 97 th centile are obese; younger children (aged 2-5 years) must be over the 97 th centile to be considered overweight and more than the 99.9 th centile to be considered obese. ${ }^{1} \mathrm{~A}$ recent Canadian Health Measures Survey (2009-2011) reported obesity prevalence among 5- to 17 -year-olds at $11.7 \%$, with an additional $19.8 \%$ classified as overweight. ${ }^{2}$ In the United States, obesity prevalence among 2- to 19-year-olds (2009-2010) was reported at $16.9 \%$, with another $14.9 \%$ considered overweight. ${ }^{3}$ Obesity that begins in childhood usually persists into adulthood ${ }^{4}$ and is associated with adverse outcomes including metabolic, cardiovascular, musculoskeletal, neurologic, gastrointestinal, respiratory and psychosocial disturbances. ${ }^{5-10}$
\end{abstract}

The predicted increase in childhood obesity has intensified the urgency of improving treatment approaches for the pediatric population.

Treatment of childhood and adolescent obesity is an active area of research, and a number of systematic reviews have been published recently. ${ }^{11-17}$ Comprehensive behavioural interventions including changes in diet, physical activity and lifestyles involving individual patients or families are

Competing interests: None declared.

This article has been peer reviewed.

Correspondence to: Leslea Peirson, peirson@mcmaster.ca

CMAJ Open 2015.DOI:10.9778/cmajo.20140047 
commonly used and generally considered primary modes of treatment. ${ }^{18-21}$ Recent research has focused on establishing the efficacy of combining pharmacological agents such as orlistat with conventional behavioural interventions, especially in adolescents with severe obesity, but these drugs are associated with potential adverse events. ${ }^{22-24} \mathrm{We}$ aimed to provide an updated synthesis of the evidence on benefits and harms of overweight and obesity treatment interventions for children and adolescents feasible for use in or referral from primary care, and we examined the features of efficacious interventions.

\section{Methods}

\section{Search strategy}

A recent high-quality review (9/11 AMSTAR $^{25}$ rating) by the US Preventive Services Task Force examined the effectiveness of weight management programs for children with overweight and obesity. ${ }^{17}$ We evaluated their search and determined that it addressed our key questions. To avoid duplication, we planned to bring forward any of their included studies that met our cri-

\section{Box 1: PICOS (population, interventions, comparators,} outcomes and settings) criteria

\section{Population}

- Children and youth aged 2-18 yr with overweight or obesity (body mass index [BMI] > 85th percentile for age and sex)

Interventions

- Behavioural (diet, exercise, lifestyle), pharmacological (orlistat) or combined treatments for weight loss or management

Comparators

- Treatment effectiveness: no intervention, usual care, placebo or minimal intervention (e.g., newsletter or single information session on healthy living)

- Treatment harms: any type of comparison group or no comparison group

Outcomes

- Treatment effectiveness: primary weight outcomes: changes in BMI, BMI z-score and prevalence of overweight or obesity; secondary health outcomes: changes in total cholesterol, highand low-density lipoproteins, triglycerides, fasting blood glucose, systolic and diastolic blood pressure, overall quality of life and physical fitness (measured using the multistage 20metre shuttle run test) ${ }^{26}$

- Treatment harms: any adverse events, serious adverse events (requiring admission to hospital or urgent medical care), gastrointestinal events, withdrawal from study due to adverse events

Settings

- Generalizable to Canadian primary care or feasible for use in or referral from primary care; interventions should be initiated through (or feasible within) a primary care setting and (could be) delivered by a health care professional (e.g., physician, psychologist, nurse, dietician)

- Surgical and metabolic unit interventions were excluded as representing a level of obesity and comorbid conditions that would be less commonly used as referral point from primary care teria. To update the evidence we used the same search strategy with 3 modifications: we did not use the Database of Abstracts of Reviews of Effects (DARE) or Education Resources Information Center (ERIC) database, but we added Embase; we changed the dates covered in the search; and we added a filter to limit studies to those published in English or French given our limited resources for handling papers in multiple languages. We searched Embase, MEDLINE, the Cochrane Central Register of Controlled Trials and PsycINFO from Jun. 10, 2008 (the date of the last US Preventive Services Task Force search) to Aug. 28, 2013 (our search strategy is outlined in Appendix 1, available at www.cmajopen.ca/content/3/1/E35 /suppl/DC1). In addition, we searched the reference lists of included studies and pertinent reviews for additional relevant studies not captured by our search.

\section{Inclusion and exclusion criteria}

Details regarding the population, interventions, comparators, outcomes and settings (PICOS) criteria for this review are provided in Box 1, and the inclusion and exclusion criteria are shown in Box 2.

\section{Box 2: Inclusion and exclusion criteria}

Studies were included if they met the following criteria:

- Trials of behavioural (diet, exercise, lifestyle strategies), pharmacological (orlistat) or combined (behavioural and pharmacological) weight loss treatment or management

- Intervention targeted children and youth aged 2-18 yr with overweight or obesity (body mass index [BMI] $>85$ th percentile for age and sex)

- Randomized controlled trial with a no intervention, usual care, placebo or minimal component (e.g., single newsletter or information session on general health) comparison group

- Reported data for one or more specified weight outcomes (change in BMI, BMI z-score or prevalence of overweight or obesity)

- Reported data for outcomes of interest at least 6 months after baseline assessment

- Enrolled at least 10 participants in each group

- If a study reported data for harms of treatment, they were included regardless of the above restrictions on study design, comparison group, weight outcome reporting, timing of assessment or sample size

- Results were published in English or French

Studies were excluded if:

- Treatment involved changes in the built environment (e.g., neighbourhood design, transportation options, access to playgrounds or green space), surgery or drugs other than orlistat (i.e., drugs not approved for weight loss by Health Canada)

- The study specifically enrolled participants who had an eating disorder or a condition in which weight gain was a cardinal manifestation (e.g., Prader-Willi syndrome, polycystic ovarian syndrome, pregnancy)

- Intervention was conducted in an inpatient hospital setting or involved a faith-based program

- Published results were only available in a language other than English or French 


\section{Study selection, quality assessment and data abstraction}

Titles and abstracts were reviewed in duplicate. Citations marked for inclusion by either team member underwent fulltext screening, which was also done independently by 2 people. One person completed full abstraction, and a second person verified extractions. Data were checked again before analysis. We assessed randomized controlled trials using the Cochrane risk-of-bias tool. ${ }^{27} \mathrm{We}$ determined the overall strength of the evidence using the Grading of Recommendations Assessment, Development and Evaluation system (GRADEpro version 3.2); we applied ratings of high, moderate, low or very low based on assessments of 5 domains of the evidence (risk of bias, indirectness, imprecision, inconsistency and reporting bias). We resolved all conflicts through discussion between raters and, if necessary, through consultation with review team members.

\section{Data analysis}

For meta-analyses, we used means and standard deviations (SD) for continuous outcomes (e.g., BMI) and counts data for binary outcomes (e.g., prevalence, adverse events). Whenever possible, we used immediate posttreatment data; otherwise, we selected the data point closest to the end of the intervention and at least 6 months after baseline. If studies reported results for boys and for girls, we entered these data separately. For studies with multiple intervention arms, we combined data from similar groups (e.g., 2 lifestyle arms, 1 delivered to families, 1 delivered only to parents) to do a pairwise comparison with the control group. ${ }^{27}$ We used Cochran Q $(\alpha=0.05)$ and $I^{2}(\geq 75 \%=$ high heterogeneity) statistics to quantify statistical heterogeneity between studies. We used RevMan version 5.3, STATA version 12 and GRADEpro for statistical analyses.

We chose standardized mean difference (SMD) as a summary measure of effect to allow us to combine data for BMI and BMI z-score in a single meta-analysis; if a study reported both outcomes, we used the nonstandardized data. This strategy, which is consistent with the approach taken in other reviews ${ }^{17,28}$ increases the pool of studies, thereby increasing the power to detect a difference in weight change between groups. We used the DerSimonian and Laird random effects model with inverse variance ${ }^{29}$ to generate SMDs for BMI and BMI z-score $(<0.2=$ very small effect; $\geq 0.2$ to $<0.5=$ small effect; $\geq 0.5$ to $<0.8=$ medium effect; $\geq 0.8=$ large effect).$^{30}$ We used this same random effects model ${ }^{20}$ to generate summary measures of effect in the form of mean differences (MDs) for the other continuous outcomes and risk ratios (RRs) for binary outcomes. For harms, we calculated absolute risk increase (ARI) and number-needed-to-harm $(\mathrm{NNH})$; the latter were calculated using the absolute numbers computed by the GRADE software. GRADE estimates the absolute number per million using the control group event rate and RR with the $95 \%$ confidence interval (CI) obtained from the meta-analysis. For BMI and BMI z-score, we conducted subgroup analyses based on the focus of intervention - behavioural or pharmacological (orlistat) plus behavioural — and then only for behavioural approaches based on intervention type (diet, exercise, diet plus exercise, lifestyle), intervention duration ( $\leq 12 \mathrm{mo},>12 \mathrm{mo}$ ), age group (2-12 yr, 13-18 yr), intervention target (individual, family) and study risk of bias rating (low, unclear, high).

Efficacious interventions were identified from studies in the $\mathrm{BMI}$ and BMI z-score meta-analysis that significantly favoured treatment. Our choice of intervention characteristics to examine (target sex and age, estimated number or frequency of sessions, group sessions, family involvement and staff training) was informed by a similar list in a previous systematic review, ${ }^{17}$ to which we added intervention duration, type and setting, based on our belief that primary care professionals might want to consider these additional features when making referrals or recommending programs to patients and their families.

\section{Results}

\section{Search and selection}

We conducted title and abstract screening on 2716 citations located through our updated search (Figure 1). We added 15 older studies that appeared in the US Preventive Services Task Force review ${ }^{17}$ to the pool of recently published papers retained for full-text screening $(n=319)$. We included 31 studies (published in 37 papers) in our analysis, 9 of which were brought forward from the US Preventive Services Task Force review, ${ }^{31-39}$ and 22 of which were identified from the more recent literature. ${ }^{40-61}$ Characteristics of included studies Characteristics of the included studies are summarized in Table 1 . All but 1 study ${ }^{41}$ included both male and female participants. Most $(n=23)$ studies involved elementary schoolaged children (mean age at baseline 5-12 yr), 19 studies involved children and youth with overweight or obesity, and 11 targeted children and youth with obesity only. Multicomponent behavioural interventions (lifestyle or diet plus exercise) were used in 26 studies, and a combined pharmacological (orlistat) and behavioural approach was used in 2 studies. Interventions targeted families in 18 studies and individuals in 13 studies. Almost all $(n=28)$ of the interventions lasted one year or less, and more than half $(n=18)$ lasted between 2 and 6 months. Additional details of the individual studies are provided in Appendix 2 (available at www.cmajopen.ca /content/3/1/E35/suppl/DC1).

Twenty-eight of the studies were rated as having unclear or high risk of bias for the weight outcomes (Table 2), primarily due to the lack of information about or lack of procedures to ensure random sequence generation, allocation concealment and blinding of participants, personnel and outcome assessment.

\section{Change in BMI and BMI z-score}

Thirty studies were included in the meta-analysis assessing change in BMI and BMI z-score. ${ }^{31-60}$ We found a significantly lowered BMI and BMI z-score in the intervention group compared with the control group with a medium size of effect (Figure 2 and Table 3). The subgroup analysis based on intervention focus (i.e., behavioural alone v. pharmacological plus behavioural) showed no difference in reduction of BMI and BMI z-score (Table 3). Further sensitivity analyses 
for behavioural intervention studies showed no difference in reduction of $\mathrm{BMI}$ and $\mathrm{BMI} \mathrm{z}$-score across treatment types, intervention duration, participants' age or risk-of-bias rating (Table 3). There was, however, a difference in reduction in $\mathrm{BMI}$ and $\mathrm{BMI} \mathrm{z}$-score depending on the target of intervention; treatments focusing on the individual children (e.g., classroom interventions with no parent involvement) had a large effect, whereas family-based approaches (e.g., active parent involvement) showed a smaller, but still significant, effect (Table 3 ). The study that could not be pooled found no significant $(p=0.86)$ treatment effect on BMI z-score for a 6 -month lifestyle intervention targeted at children aged $5-8$ years. ${ }^{61}$

Four trials reported follow-up data (6-12 mo postintervention). ${ }^{32,41,57,60}$ Meta-analysis showed significantly lower BMI and $\mathrm{BMI} z$-score in the intervention group compared with the control group by the end of treatment (Table 3). However, there was no difference in BMI and BMI z-score between groups at the time of postintervention to 1-year follow-up.

\section{Change in BMI}

We included 21 trials that assessed change in BMI in our meta-analysis. ${ }^{31,32,34-37,39,42,45-53,56-59}$ Intervention participants had a significantly greater reduction in BMI compared with participants in the control groups (Table 4). Our subgroup analysis based on intervention focus (i.e., behavioural alone v. pharmacological plus behavioural) showed no significant difference in reduction of BMI.

\section{Change in prevalence of overweight/obesity}

Three low-quality trials (downgraded for risk of bias and imprecision) provided results for change in prevalence of overweight or obesity that could not be pooled because they used different weight categories (overweight, overweight/obesity, obesity), and 1 study did not provide events data..$^{35,36,50}$ The 2 studies that included elementary school-aged children reported prevalence 9 months after 3-month family-based interventions involving diet and exercise. No difference between groups was seen in 1 study $(n=242)(\mathrm{RR} 0.93,95 \%$

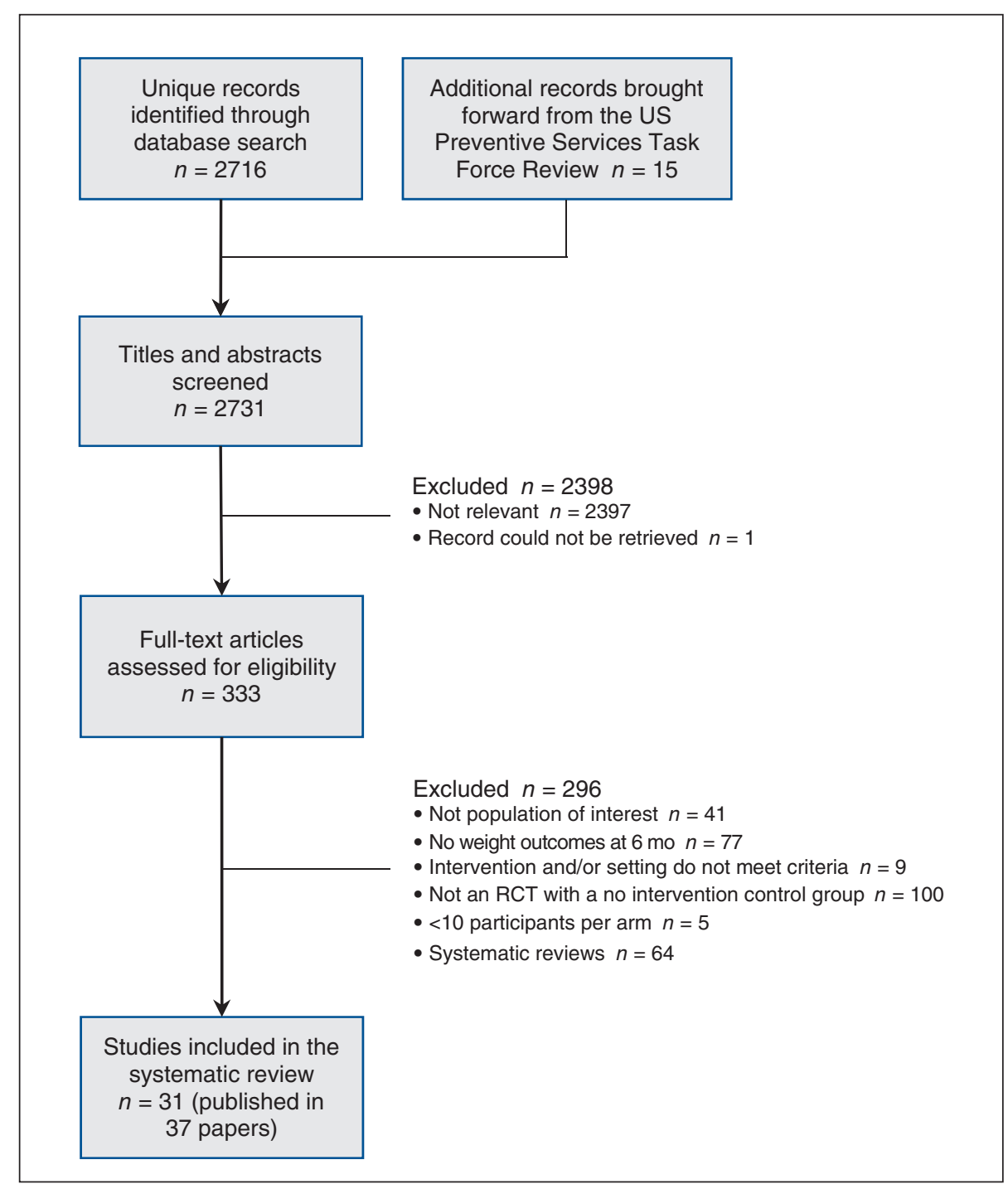

Figure 1: Selection of studies for inclusion in the systematic review and meta-analyses. 
CI 0.82 to 1.06$){ }^{50}$ in the second study $(n=40)$, there was a $5 \%-6 \%$ reduction in obesity prevalence in the intervention group. ${ }^{36}$ The third study reported no significant difference in change in prevalence between intervention and control groups 3 months after a 4-month lifestyle program for youth with overweight or obesity youth $(n=38)(\mathrm{RR} 0.90,95 \%$ CI 0.54 to 1.46$).{ }^{35}$

\section{Change in other health outcomes}

We examined changes from baseline to postintervention in

Table 1: Characteristics of included studies ${ }^{1}$

\begin{tabular}{|c|c|c|c|c|c|c|c|c|c|}
\hline \multirow[b]{2}{*}{ Study } & \multirow{2}{*}{$\begin{array}{l}\text { Mean age at } \\
\text { baseline, yr pa }\end{array}$} & \multirow{2}{*}{$\begin{array}{l}\text { No. of } \\
\text { articipants }\end{array}$} & \multirow{2}{*}{$\begin{array}{l}\text { Baseline weight } \\
\text { category }\end{array}$} & \multicolumn{4}{|c|}{ Intervention } & \multirow[b]{2}{*}{ Location } & \multirow[b]{2}{*}{ Date } \\
\hline & & & & Type & Target & Comparator & Length, mo & & \\
\hline Bäcklund et al..$^{52}$ & 10 & 105 & Overweight + obese & Lifestyle & Family & No intervention & 24 & Sweden & 2011 \\
\hline Bryant et al. ${ }^{40}$ & 11 & 70 & Obese & Lifestyle & Family & Wait list & 12 & UK & 2011 \\
\hline Chanoine et al. ${ }^{31}$ & 14 & 539 & Obese & $\begin{array}{c}\text { Orlistat, } \\
\text { diet+exercise }\end{array}$ & Individual & Placebo & 12 & US + Canada & 2005 \\
\hline Coppins et al. ${ }^{43}$ & 10 & 65 & Overweight + obese & Lifestyle & Family & No intervention & 12 & UK & 2011 \\
\hline Croker et al. ${ }^{42}$ & 10 & 72 & Obese & Lifestyle & Individual & Wait list & 6 & UK & 2012 \\
\hline DeBar et al. ${ }^{41}$ & 14 & 208 & Overweight + obese & Lifestyle & Individual & $\begin{array}{c}\text { Minimal } \\
\text { component }\end{array}$ & 5 & US & 2012 \\
\hline Doyle et al. ${ }^{37}$ & 15 & 83 & Overweight + obese & Lifestyle & Individual & $\begin{array}{c}\text { Minimal } \\
\text { component }\end{array}$ & 4 & US & 2008 \\
\hline Ebbeling et al. ${ }^{57}$ & 15 & 224 & Overweight + obese & Diet & Individual & No intervention & 12 & US & 2012 \\
\hline Epstein et al. ${ }^{38}$ & 6 & 70 & Overweight + obese & Lifestyle & Family & $\begin{array}{c}\text { Minimal } \\
\text { component }\end{array}$ & 24 & US & 2008 \\
\hline Golley et al. ${ }^{33}$ & 8 & 111 & Overweight + obese & Lifestyle & Family & $\begin{array}{c}\text { Minimal } \\
\text { component }\end{array}$ & 12 & Australia & 2007 \\
\hline Janicke et al. ${ }^{54}$ & 11 & 93 & Overweight + obese & Lifestyle & Family & Wait list & 4 & US & 2009 \\
\hline Lisón et al. ${ }^{56}$ & 11 & 110 & Overweight + obese & Diet+exercise & Individual & Usual care & 6 & Spain & 2012 \\
\hline Lochrie et al. ${ }^{60}$ & 10 & 130 & Overweight + obese & Lifestyle & Family & $\begin{array}{c}\text { Minimal } \\
\text { component }\end{array}$ & 6 & US & 2013 \\
\hline Maahs et al. ${ }^{39}$ & 16 & 40 & Overweight + obese & $\begin{array}{c}\text { Orlistat, } \\
\text { diet+exercise }\end{array}$ & Individual & Placebo & 6 & US & 2006 \\
\hline Maddison et al. ${ }^{46}$ & 12 & 322 & Overweight + obese & Exercise & Individual & No intervention & 6 & New Zealand & 2011 \\
\hline McCallum et al. ${ }^{34}$ & 7 & 163 & Overweight + obese & Lifestyle & Family & No intervention & 3 & Australia & 2007 \\
\hline Nemet et al. ${ }^{36}$ & 11 & 54 & Obese & Diet+exercise & Family & Usual care & 3 & Israel & 2005 \\
\hline O'Connor et al. ${ }^{61}$ & 7 & 40 & Overweight + obese & Lifestyle & Family & Wait list & 6 & US & 2011 \\
\hline Racine et al. ${ }^{49}$ & 9 & 62 & Overweight + obese & Diet & Individual & Placebo & 6 & US & 2010 \\
\hline Reinehr et al. ${ }^{48}$ & 11 & 71 & Overweight & Lifestyle & Individual & No intervention & 6 & Germany & 2010 \\
\hline Sacher et al. ${ }^{53}$ & 10 & 116 & Obese & Lifestyle & Family & Usual care & 6 & UK & 2010 \\
\hline Saelens et al. ${ }^{35}$ & 14 & 44 & Overweight + obese & Lifestyle & Individual & Usual care & 4 & US & 2002 \\
\hline Savoye et al. ${ }^{32}$ & 12 & 174 & Obese & Lifestyle & Family & Usual care & 12 & US & 2007 \\
\hline Taveras et al. ${ }^{45}$ & 5 & 445 & Overweight + obese & Lifestyle & Family & Usual care & 12 & US & 2011 \\
\hline Toulabi et al. ${ }^{58}$ & 16 & 152 & Obese & Diet+exercise & Individual & No intervention & 24 & Iran & 2012 \\
\hline Vos et al. ${ }^{55}$ & 13 & 81 & Obese & Lifestyle & Family & Wait list & 3 & Netherlands & 2011 \\
\hline Wafa et al. ${ }^{44}$ & 10 & 107 & Obese & Lifestyle & Family & No intervention & 6 & Malaysia & 2011 \\
\hline Wake et al. ${ }^{50}$ & 7 & 258 & Overweight + obese & Diet+exercise & Family & Usual care & 3 & Australia & 2009 \\
\hline Wake et al. ${ }^{59}$ & 7 & 118 & Obese & Lifestyle & Family & No intervention & 12 & Australia & 2013 \\
\hline Waling et al. ${ }^{47}$ & 10 & 105 & Overweight + obese & Diet+exercise & Family & No intervention & 12 & Sweden & 2010 \\
\hline Weigel et al. ${ }^{51}$ & 11 & 73 & Obese & Diet+exercise & Individual & No intervention & 12 & Germany & 2008 \\
\hline
\end{tabular}


cardiometabolic outcomes associated with treatment. Blood pressure outcomes were reported in 5 studies, ${ }^{31,48,51,53,55}$ and significant changes in systolic (MD $-3.42,95 \%$ CI -6.65 to -0.29 ) and diastolic (MD $-3.39,95 \% \mathrm{CI}-5.17$ to -1.60$)$ blood pressure were seen (Table 4). No significant differences in any lipid variables (total cholesterol, low- or high-density lipoproteins or triglycerides) were seen (Table 4). ${ }^{31,32,39,41,49,55}$ One study provided data on fasting glucose levels, and no significant difference was seen (Table 4). ${ }^{31}$ None of the included studies reported changes in physical fitness as measured by laps or stages of the multistage fitness test. ${ }^{26}$

Six trials examined changes in quality of life after treatment for obesity. ${ }^{34,41,42,44,50,55}$ Five studies used the 23-item Pediatric Quality of Life inventory (PedsQL), ${ }^{62}$ and 1 study used the 37-item DISABKIDS Chronic Generic Measure. ${ }^{63}$ Both tools are validated instruments for use with children and adolescents, and access domains of physical, emotional, social and psychosocial functioning. Meta-analysis showed a significant

Table 2: Risk of bias assessment ${ }^{27}$ of included trials

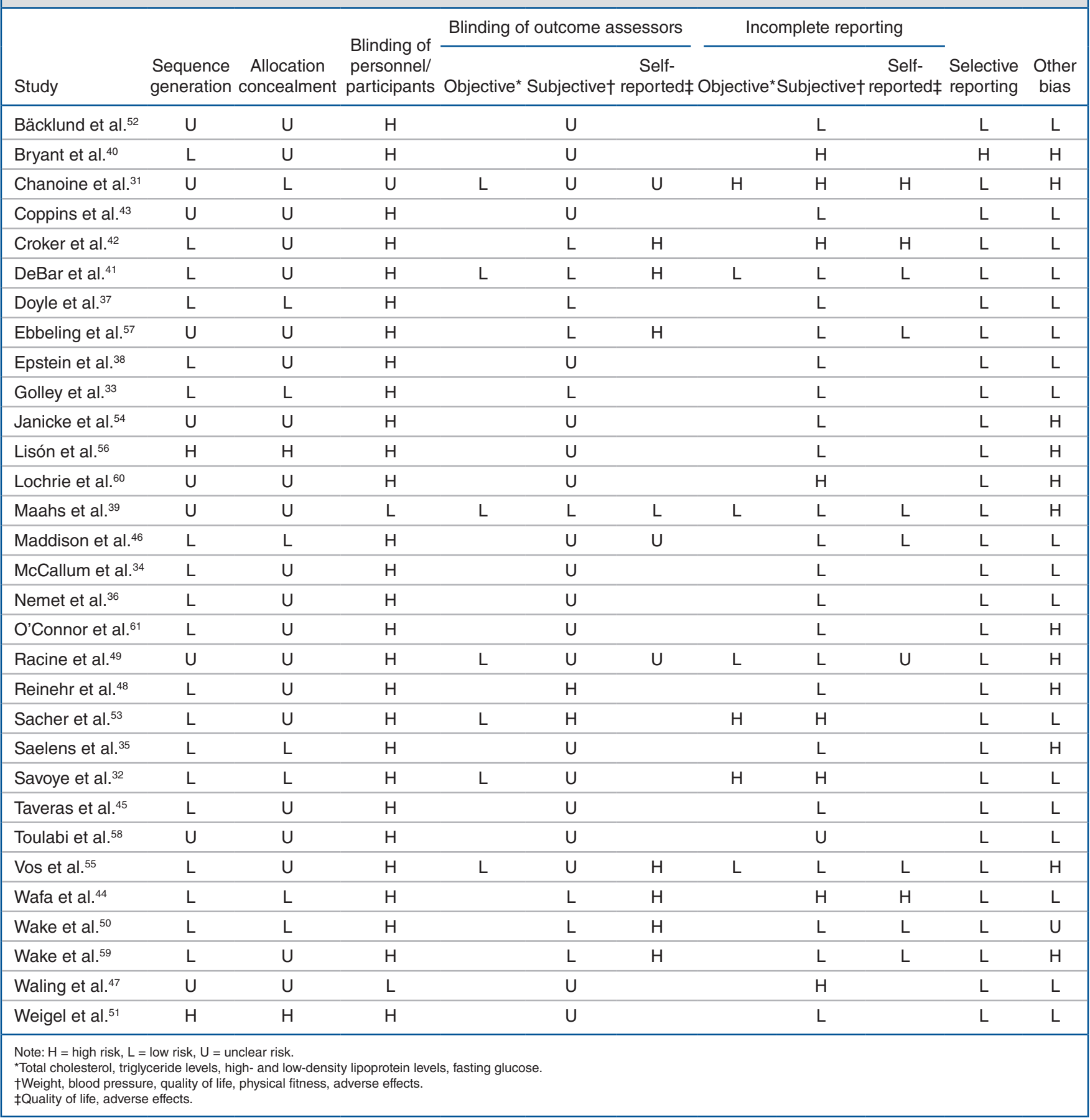




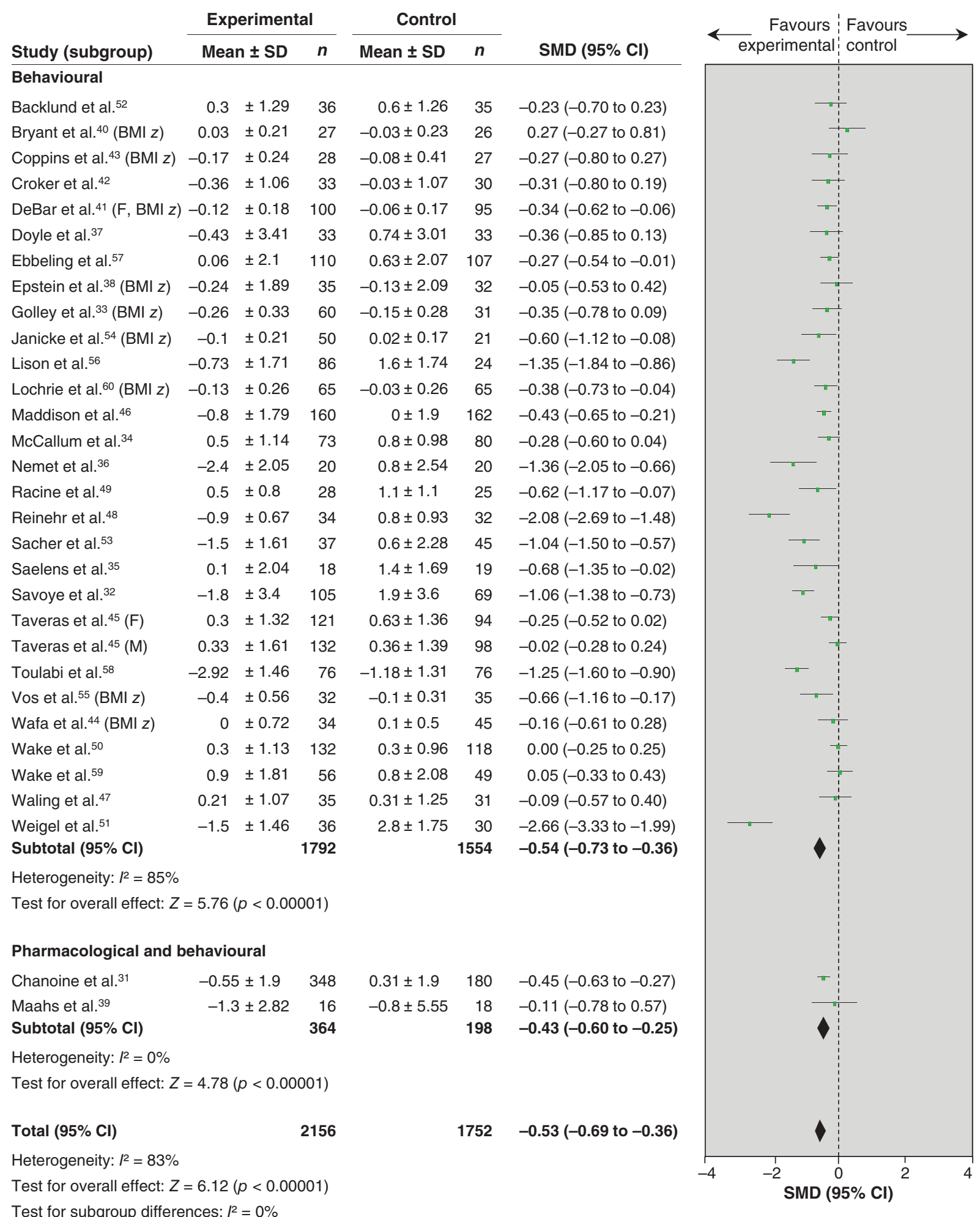

Figure 2: Effect of treatment interventions on body mass index and body mass index z-score (behavioural, pharmacological plus behavioural). Note: $\mathrm{BMI} z$ = body mass index $\mathrm{z}$-score, $\mathrm{F}=$ female, $\mathrm{M}=$ male, $\mathrm{SMD}=$ standardized mean difference. 


\section{OPEN}

Research

improvement in overall quality-of-life scores in the intervention groups compared with the control groups (SMD 2.10, $95 \%$ CI 0.60 to 3.60 , Table 4 ).

\section{Harms}

Nine studies provided data for adverse effects of treatment. ${ }^{31,39,42,46,49,50,57-59}$ Meta-analyses showed no significant differences between intervention and control groups for the categories of any adverse events, serious adverse events (requiring admission to hospital or urgent medical care) and study withdrawal due to adverse events (Table 5). One study ${ }^{31}$ reported that gastrointestinal disturbances (e.g., bloating and diarrhea) were significantly more common with orlistat treatment compared with the control (RR 3.77, 95\% CI 2.56 to 5.55; number needed to harm 3, 95\% CI 2 to 5) (Table 5).

\section{Features of efficacious interventions}

Sixteen studies showed a significant benefit for participants in treatment arms compared with control arms in terms of reduced
$\mathrm{BMI}$ and $\mathrm{BMI} \mathrm{z}$-score (Figure 2). We designated the interventions in these studies as efficacious (Table 6 and Appendix 3, available at www.cmajopen.ca/content/3/1/E35/suppl/DC1).

The focus of the behavioural interventions varied and included diet $(n=2)$, exercise $(n=1)$, diet and exercise combined $(n=4)$ and lifestyle $(n=8)$. Eleven interventions involved group sessions, 5 used individual sessions, and almost all interventions $(n=12)$ incorporated parental or family involvement. $32,35,36,41,48,49,51,53-55,58,60$ Three interventions used technology to facilitate interaction between participants and study personnel or as a means of delivering information or encouraging physical activity. Duration of interventions ranged from 3 months to 2 years. All but 1 intervention lasted 1 year or less, and most $(n=11)$ were in place for 6 months or less. The number and frequency of sessions varied; however, most strategies involved weekly or biweekly contact with participants; a few interventions were more intense, interacting with participants twice or more each week. Most interventions were offered to male and female participants $(n=14)$ and two-thirds

Table 3: Overall and subgroup analyses for primary outcomes

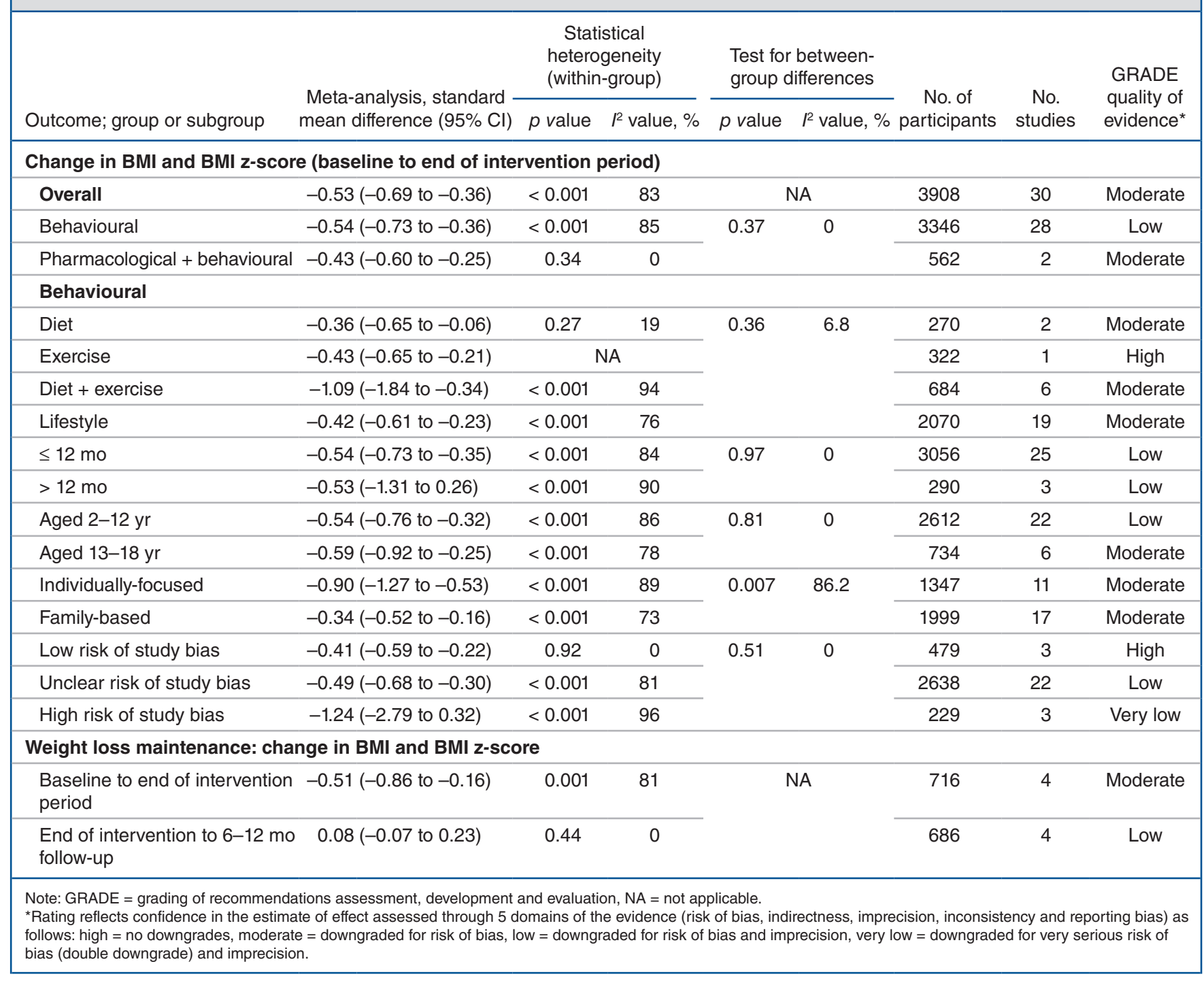


Table 4: Overall and subgroup analyses for primary and secondary outcomes

\begin{tabular}{|c|c|c|c|c|c|c|c|c|}
\hline \multirow{2}{*}{$\begin{array}{l}\text { Outcome; group or } \\
\text { subgroup }\end{array}$} & \multirow{2}{*}{$\begin{array}{c}\text { Meta-analysis, } \\
\text { mean difference }(95 \% \mathrm{Cl})\end{array}$} & \multicolumn{2}{|c|}{$\begin{array}{l}\text { Statistical heterogeneity } \\
\text { (within-group) }\end{array}$} & \multicolumn{2}{|c|}{$\begin{array}{l}\text { Test for between-group } \\
\text { differences }\end{array}$} & \multirow{2}{*}{$\begin{array}{l}\text { No. } \\
\text { participants }\end{array}$} & \multirow{2}{*}{$\begin{array}{l}\text { No. of } \\
\text { studies }\end{array}$} & \multirow{2}{*}{$\begin{array}{l}\text { GRADE } \\
\text { quality of } \\
\text { evidence* }\end{array}$} \\
\hline & & $p$ value & $R^{2}$ value, $\%$ & $p$ value & $I^{2}$ value, $\%$ & & & \\
\hline \multicolumn{9}{|c|}{ Change in body mass index $\left(\mathrm{kg} / \mathrm{m}^{2}\right)$ (baseline to immediate post) } \\
\hline Overall & $-1.12 \quad(-1.52$ to -0.72$)$ & $<0.00001$ & 92 & \multicolumn{2}{|c|}{ NA } & 3100 & 21 & Moderate \\
\hline Behavioural & $-1.15 \quad(-1.59$ to -0.72$)$ & $<0.00001$ & 93 & \multirow[t]{2}{*}{0.29} & 10.4 & 2538 & 19 & Moderate \\
\hline $\begin{array}{l}\text { Pharmacological + } \\
\text { behavioural }\end{array}$ & $-0.86 \quad(-1.19$ to -0.52$)$ & 0.81 & 0 & & & 562 & 2 & Moderate \\
\hline \multicolumn{9}{|c|}{ Change in systolic blood pressure ( $\mathrm{mmHg}$ ) (baseline to immediate post) } \\
\hline Overall & $-3.42(-6.65$ to -0.29$)$ & 0.003 & 75 & & A & 808 & 5 & Moderate \\
\hline \multicolumn{9}{|c|}{ Change in diastolic blood pressure ( $\mathrm{mmHg}$ ) (baseline to immediate post) } \\
\hline Overall & $-3.39(-5.17$ to -1.60$)$ & 0.11 & 47 & & A & 808 & 5 & Moderate \\
\hline \multicolumn{9}{|c|}{ Change in total cholesterol (mmol/L) (baseline to immediate post) } \\
\hline Overall & $-0.06 \quad(-0.19$ to 0.07$)$ & 0.03 & 63 & & A & 904 & 5 & Low \\
\hline \multicolumn{9}{|c|}{ Change in low-density lipoprotein cholesterol ( $\mathrm{mmol} / \mathrm{L})$ (baseline to immediate post) } \\
\hline Overall & $0.01 \quad(-0.11$ to 0.13$)$ & 0.009 & 70 & & A & 904 & 5 & Low \\
\hline \multicolumn{9}{|c|}{ Change in high-density lipoprotein cholesterol (mmol/L) (baseline to immediate post) } \\
\hline Overall & $-0.02(-0.05$ to 0.01$)$ & 0.16 & 37 & & A & 971 & 6 & Low \\
\hline \multicolumn{9}{|c|}{ Change in triglycerides (mmol/L) (baseline to immediate post) } \\
\hline Overall & $-0.02 \quad(-0.12$ to 0.09$)$ & 0.19 & 35 & & A & 937 & 5 & Low \\
\hline \multicolumn{9}{|c|}{ Change in fasting glucose ( $\mathrm{mmol} / \mathrm{L})$ (baseline to immediate post) } \\
\hline Overall & $0.06 \quad(-0.29$ to 0.17$)$ & NA & & & A & 528 & 1 & Low \\
\hline \multicolumn{9}{|c|}{ Change in overall quality of life (pediatric quality of life inventory or DISABKIDS questionnaire) (baseline to immediate post) } \\
\hline Overall & $2.10 \quad(0.60$ to 3.60$)$ & 0.37 & 8 & & A & 777 & 6 & Moderate \\
\hline
\end{tabular}

Table 5: Subgroup analyses for harms

Effect

Absolute risk No. needed to

Outcome, subgroup Risk ratio $(95 \% \mathrm{Cl})$ increase, $\%$ harm $(95 \% \mathrm{Cl})$
Statistical heterogeneity Test for between(within-group) group differences,

GRADE

No. of No. of quality of $p$ value $\quad I^{2}$ value, $\% \quad p$ value $I^{2}$ value, \% participants studies evidence

\section{Any adverse events}

\begin{tabular}{|c|c|c|c|c|c|c|c|c|}
\hline Behavioural & Not estimable† & - & - & NA & NA & 482 & 3 & Moderate \\
\hline Pharmacological + & 1.03 (0.99 to 1.08$)$ & - & - & NA & & 533 & 1 & Low \\
\hline
\end{tabular}

behavioural

\section{Serious adverse events}

\begin{tabular}{|c|c|c|c|c|c|c|c|c|c|}
\hline Behavioural & 0.51 (0.09 to 2.73 ) & - & - & NA & 0.37 & 0 & 322 & 1 & Moderate \\
\hline Pharmacological + & 1.25 (0.46 to 3.35$)$ & - & - & 0.56 & & & 573 & 2 & Low \\
\hline
\end{tabular}

behavioural

\section{Gastrointestinal events}

\begin{tabular}{|c|c|c|c|c|c|c|c|c|}
\hline $\begin{array}{l}\text { Pharmacological + } \\
\text { behavioural }\end{array}$ & 3.77 (2.56 to 5.55$)$ & 36.7 & 3 (2 to 5$)$ & NA & NA & 533 & 1 & Moderate \\
\hline \multicolumn{9}{|c|}{ Study withdrawal due to adverse events } \\
\hline Pharmacological + & 2.49 (0.79 to 7.87$)$ & - & - & 0.45 & NA & 573 & 2 & Low \\
\hline
\end{tabular}

behavioural 


\section{OPEN}

$(n=10)$ targeted elementary school-aged children. About half $(n=7)$ of the interventions were done in the United States, and one-third $(n=5)$ took place in European countries.

The efficacious intervention that used a pharmacological plus behavioural strategy targeted male and female adolescents with obesity in Canada and the United States. The treatment combined a $120 \mathrm{mg}$ dose of orlistat taken 3 times daily with a standard dietary intervention and encouragement to engage in regular physical activity. After a 2-week lead-in period, the intervention ran for 1 year.

\begin{tabular}{|c|c|c|c|c|c|c|c|c|c|c|c|}
\hline \multirow[b]{2}{*}{ Study } & \multirow[b]{2}{*}{ Sex } & \multirow{2}{*}{$\begin{array}{c}\text { Mean } \\
\text { age at } \\
\text { baseline, } \\
\text { yr }\end{array}$} & \multirow{2}{*}{$\begin{array}{c}\text { Baseline } \\
\text { weight } \\
\text { category }\end{array}$} & \multicolumn{4}{|c|}{ Intervention } & \multicolumn{2}{|c|}{ Sessions } & \multirow{2}{*}{$\begin{array}{c}\text { Parental } \\
\text { involvement }\end{array}$} & \multirow{2}{*}{$\begin{array}{l}\text { Technology- } \\
\text { based }\end{array}$} \\
\hline & & & & mo & Estimated no. of sessions & Focus & Target & Group & Individual & & \\
\hline $\begin{array}{l}\text { DeBar } \\
\text { et al. }{ }^{41}\end{array}$ & Female & 14 & $\begin{array}{l}\text { Overweight } \\
+ \text { obese }\end{array}$ & 6 & $\begin{array}{l}28 \text { total; } 16 \text { group meetings } \\
\text { for teens, } 12 \text { parent sessions }\end{array}$ & Lifestyle & Individual & Yes & - & Yes & - \\
\hline $\begin{array}{l}\text { Ebbeling } \\
\text { et al. } .^{57}\end{array}$ & Mixed & 15 & $\begin{array}{l}\text { Overweight } \\
+ \text { obese }\end{array}$ & 12 & $\begin{array}{l}3 \text { check-in visits, } 12 \text { phone } \\
\text { calls }\end{array}$ & Diet & Individual & Yes & - & - & Yes \\
\hline $\begin{array}{l}\text { Janicke } \\
\text { et al. } .^{54}\end{array}$ & Mixed & 11 & $\begin{array}{l}\text { Overweight } \\
+ \text { obese }\end{array}$ & 4 & 12 group sessions & Lifestyle & Family & Yes & - & Yes & - \\
\hline $\begin{array}{l}\text { Lison } \\
\text { et al. }{ }^{56}\end{array}$ & Mixed & 11 & $\begin{array}{l}\text { Overweight } \\
+ \text { obese }\end{array}$ & 6 & 120 exercise sessions & $\begin{array}{l}\text { Diet }+ \\
\text { exercise }\end{array}$ & Individual & $1-$ & Yes & - & - \\
\hline $\begin{array}{l}\text { Lochrie } \\
\text { et al. }{ }^{0}\end{array}$ & Mixed & 10 & $\begin{array}{l}\text { Overweight } \\
+ \text { obese }\end{array}$ & 6 & $\begin{array}{l}14 \text { ( } 8 \text { weekly, } 4 \text { bimonthly, } 2 \\
\text { monthly) }\end{array}$ & Lifestyle & Family & Yes & - & Yes & - \\
\hline $\begin{array}{l}\text { Maddison } \\
\text { et al. }{ }^{46}\end{array}$ & Mixed & 12 & $\begin{array}{l}\text { Overweight } \\
+ \text { obese }\end{array}$ & 6 & $\begin{array}{l}\text { Not specified: children } \\
\text { encouraged to meet } \\
\text { recommendations ( } 60 \text { min } \\
\text { moderate to vigorous } \\
\text { physical activity on most } \\
\text { days) }\end{array}$ & Exercise & Individual & - & - & - & Yes \\
\hline $\begin{array}{l}\text { Nemet } \\
\text { et al. }{ }^{36}\end{array}$ & Mixed & 11 & Obese & 3 & $\begin{array}{l}34 \text { total; } 24 \text { training sessions, } \\
6 \text { individual meetings with } \\
\text { dietician, } 4 \text { evening lectures }\end{array}$ & $\begin{array}{l}\text { Diet + } \\
\text { exercise }\end{array}$ & Family & Yes & Yes & Yes & - \\
\hline $\begin{array}{l}\text { Racine } \\
\text { et al. }{ }^{49}\end{array}$ & Mixed & 9 & $\begin{array}{l}\text { Overweight } \\
+ \text { obese }\end{array}$ & 6 & 1 session with a dietician & Diet & Individual & $1-$ & Yes & Yes & - \\
\hline $\begin{array}{l}\text { Reinehr } \\
\text { et al. }{ }^{48}\end{array}$ & Mixed & 11 & Overweight & 6 & $\begin{array}{l}48 \text { total; } 37 \text { sessions for } \\
\text { children, } 6 \text { for parents, } 5 \text { for } \\
\text { families }\end{array}$ & Lifestyle & Individual & Yes & - & Yes & - \\
\hline $\begin{array}{l}\text { Sacher } \\
\text { et al. } .^{53}\end{array}$ & Mixed & 10 & Obese & 6 & $\begin{array}{l}18 \text { sessions over } 9 \text { wk (2-h } \\
\text { group sessions held twice } \\
\text { weekly) }\end{array}$ & Lifestyle & Family & Yes & - & Yes & - \\
\hline $\begin{array}{l}\text { Saelens } \\
\text { et al. }{ }^{35}\end{array}$ & Mixed & 14 & $\begin{array}{l}\text { Overweight } \\
+ \text { obese }\end{array}$ & 4 & $\begin{array}{l}1 \text { meeting with pediatrician; } \\
1 \text { wk later meeting with } \\
\text { author, } 11 \text { calls from phone } \\
\text { counselor (10-20 min } \\
\text { weekly first } 8 x \text {, biweekly last } \\
3 x \text { ) }\end{array}$ & Lifestyle & Individual & 1 & Yes & Yes & Yes \\
\hline $\begin{array}{l}\text { Savoye } \\
\text { et al. }{ }^{32}\end{array}$ & Mixed & 12 & Obese & 12 & $\begin{array}{l}2 \text { sessions per week for first } \\
6 \text { mo; biweekly next } 6 \text { mo }\end{array}$ & Lifestyle & Family & Yes & Yes & Yes & - \\
\hline $\begin{array}{l}\text { Toulabi } \\
\text { et al. } .^{58}\end{array}$ & Mixed & 16 & Obese & 24 & $\begin{array}{l}41 \text {-h weekly parents } \\
\text { sessions on nutrition; } 8 \\
45-\text { min student sessions } 2 x / \\
\text { wk on nutrition and physical } \\
\text { activity; exercises } 1 \mathrm{~h} \text { per } \\
\text { day, } 3 \mathrm{x} / \mathrm{wk} \text { for } 6 \mathrm{wk}\end{array}$ & $\begin{array}{l}\text { Diet + } \\
\text { exercise }\end{array}$ & Individual & Yes & - & Yes & - \\
\hline $\begin{array}{l}\text { Vos } \\
\text { et al. }{ }^{55}\end{array}$ & Mixed & 13 & Obese & 3 & $\begin{array}{l}7 \text { group meetings for } \\
\text { children, } 5 \text { for parents; } 1 \text { for } \\
\text { families ( } 2 \text { h } 40 \text { min } \\
\text { biweekly) }\end{array}$ & Lifestyle & Family & Yes & Yes & Yes & - \\
\hline $\begin{array}{l}\text { Weigel } \\
\text { et al. }{ }^{51}\end{array}$ & Mixed & 11 & Obese & 12 & $\begin{array}{l}2 \text { sessions per week; } \\
\text { monthly parent meetings }\end{array}$ & $\begin{array}{l}\text { Diet }+ \\
\text { exercise }\end{array}$ & Individual & Yes & - & Yes & - \\
\hline
\end{tabular}




\section{Interpretation}

The meta-analyses of BMI and BMI z-scores in this updated systematic review of treatments for overweight and obesity in children and youth showed moderate benefits for treatment compared with control, and these findings are consistent with previous reviews. ${ }^{14,15,17,64} \mathrm{We}$ used a comprehensive approach of subgrouping studies for behavioural interventions to reflect the evidence in existing literature. In addition to conventional measures of obesity, such as BMI and BMI z-score, we looked at prevalence of overweight and obesity to help quantify the clinical significance of weight loss. Although limited in the number of studies, our review of cardiometabolic outcomes suggests modest declines in BMI are accompanied by declines in blood pressure, which is consistent with other reviews. ${ }^{14,64} \mathrm{We}$ also identified improvement in quality-of-life scores. In contrast to weight loss of $5 \%-10 \%$ in adults, ${ }^{65}$ a threshold associated with improved health outcomes for children has not been established. In addition, Kolotourou and colleagues argue BMI is too restrictive an outcome, and that additional outcomes such as fitness, selfesteem, physical and sedentary activities should be measured. ${ }^{66}$

Four studies evaluated the sustainability of changes in BMI after completion of weight-management programs. Unfortunately, after 6 months, no impact of the interventions on BMI was identified. Although this result is consistent with known biological adaptations to weight loss, it highlights the challenge of introducing time-delimited weight management interventions without follow-up, the need to introduce innovative approaches to pediatric weight management and the need to identify ways of maintaining interventions over the longterm. Studies are not yet available in the pediatric population, but it is apparent that sustained weight loss is possible in adults when interventions are maintained at a lower intensity. ${ }^{67}$

\section{Limitations}

Most of the evidence was taken from studies assessed as having an unclear risk of bias, and potential reporting bias was identified across a number of outcome- and comparison-based study groupings. In our main outcome of BMI and BMI z-score, statistical heterogeneity was high. In addition, the results presented for other health outcomes should be interpreted with caution, because we only included studies that also reported our weight outcomes. Finally, including papers published only in English or French meant possible data for relevant interventions available only in other languages were not captured.

\section{Conclusion}

Behavioural interventions for treating overweight and obesity in children and youth are associated with a moderate treatment effect in terms of a lowered BMI and BMI z-score. A small treatment effect is seen in combined pharmacological and behavioural interventions. The benefits of behavioural approaches are achieved with minimal or no adverse effects, and low-intensity behavioural interventions could readily be implemented in certain primary care settings. Few studies followed participants after completion of the intervention, but those that did found differences in BMI between groups were not maintained. Given that few studies specifically targeted youth or lasted more than 12 months, future research should evaluate active maintenance interventions in adolescents with longer follow-up. Furthermore, limited evidence as to the effectiveness of combined pharmacological and behavioural interventions warrants future research in this context.

\section{References}

1. Dietitians of Canada, Canadian Paediatric Society, The College of Family Physicians of Canada, and Community Health Nurses of Canada. Promoting optimal monitoring of child growth in Canada: using the new World Health Organization growth charts. 2010. Available: www.cps.ca/en/documents /position/child-growth-charts (accessed 5 Nov. 2014).

2. Statistics Canada. Table 1: Percentage distribution of children and adolescents, by body mass index (BMI) category (based on World Health Organization cutoffs), age group and sex, household population aged 5 to 17, 2009 to 2011. In: 2009 to 2011 Canadian Health Measures Survey. Available: www.statcan.gc.ca/pub /82-003-x/2012003/article/11706/tbl/tbl1-eng.htm.

3. Ogden CL, Carroll MD, Kit BK, et al. Prevalence of obesity and trends in body mass index among US children and adolescents, 1999-2010. FAMA 2012;307:483-90.

4. Whitaker RC, Wright JA, Pepe MS, et al. Predicting obesity in young adulthood from childhood and parental obesity. N Engl f Med 1997;337:869-73.

5. Tirosh A, Shai I, Afek A, et al. Adolescent BMI trajectory and risk of diabetes versus coronary disease. N Engl 7 Med 2011;364:1315-25.

6. Juonala M, Juhola J, Magnussen CG, et al. Childhood environmental and genetic predictors of adulthood obesity: the cardiovascular risk in young Finns study. 7 Clin Endocrinol Metab 2011;96: E1542-9.

7. Morrison JA, Friedman LA, Gray-McGuire C. Metabolic syndrome in childhood predicts adult cardiovascular disease 25 years later: the Princeton Lipid Research Clinics Follow-up Study. Pediatrics 2007;120:340-5.

8. Schwimmer JB, Burwinkle TM, Varni JW. Health-related quality of life of severely obese children and adolescents. FAMA 2003;289:1813-9.

9. Wardle J, Cooke L. The impact of obesity on psychological well-being. Best Pract Res Clin Endocrinol Metab 2005;19:421-40.

10. Williams J, Wake M, Hesketh K, et al. Health-related quality of life of overweight and obese children. 7AMA 2005;293:70-6.

11. Ho M, Garnett SP, Baur LA, et al. Impact of dietary and exercise interventions on weight change and metabolic outcomes in obese children and adolescents: a systematic review and meta-analysis of randomized trials. 7 AMA Pediatr 2013;167:759-68.

12. Hoelscher DM, Kirk S, Ritchie L, et al. Position of the Academy of Nutrition and Dietetics: interventions for the prevention and treatment of pediatric overweight and obesity. 7 Acad Nutr Diet 2013;113:1375-94.

13. Kothandan SK. School based interventions versus family based interventions in the treatment of childhood obesity - a systematic review. Arch Public Health 2014;72:3.

14. Kelley GA, Kelley KS. Effects of exercise in the treatment of overweight and obese children and adolescents: a systematic review of meta-analyses. 7 Obes 2013;2013:783103.

15. Ewald H, Kirby J, Rees K, et al. Parent-only interventions in the treatment of childhood obesity: a systematic review of randomized controlled trials. 7 Public Health (Oxf) 2014;36:476-89.

16. McDonagh MS, Selph S, Ozpinar A, et al. Systematic review of the benefits and risks of metformin in treating obesity in children aged 18 years and younger. 7AMA Pediatr 2014;168:178-84.

17. Whitlock, EP, O'Connor, EA, Williams, SB, et al. Effectiveness of primary care interventions for weight management in children and adolescents: an updated, targeted systematic review for the USPSTF. no 76 of Evidence Synthesis series. Rockville (MD): Agency for Healthcare Research and Quality; 2010. Report no: 10-05144EF-1. Available: www.ncbi.nlm.nih.gov/pubmedhealth/PMH0005904/ (accessed 6 Nov. 2014).

18. Jelalian E, Saelens BE. Empirically supported treatments in pediatric psychology: pediatric obesity. 7 Pediatr Psychol 1999;24:223-48.

19. American Dietetic Association. Position of the American Dietetic Association: individual-, family-, school-, and community-based interventions for pediatric overweight. 7 Am Diet Assoc 2006;106:925-45.

20. Barlow SE. Expert committee recommendations regarding the prevention, assessment, and treatment of child and adolescent overweight and obesity: summary report. Pediatrics 2007;120(Suppl 4):S164-92.

21. Spear BA, Barlow SE, Ervin C, et al. Recommendations for treatment of child and adolescent overweight and obesity. Pediatrics 2007;120(Suppl 4):S254-88.

22. US Food and Drug Administration. Xenical approval letter; 2014. NDA 20-766/S-018. Available: www.accessdata.fda.gov/drugsatfda_docs/appletter /2003/20766se5-018ltr.pdf (accessed 6 Nov. 2014).

23. Iughetti L, China M, Berri R, et al. Pharmacological treatment of obesity in children and adolescents: present and future. 7 Obes 2011; 2011:928165.

24. Agency for Healthcare Research and Quality. Pharmacological and surgical 
treatment of obesity. no 103 of Evidence Report/Technology Assessment. 2004. Available: http://archive.ahrq.gov/clinic/epcsums/obesphsum.htm (accessed 6 Nov. 2014)

25. Shea BJ, Grimshaw JM, Wells GA, et al. Development of AMSTAR: a measurement tool to assess the methodological quality of systematic reviews. $B M C$ Med Res Methodol 2007;7:10.

26. Léger LA, Mercier D, Gadoury C, et al. The multistage 20 metre shuttle run test for aerobic fitness. 7 Sports Sci 1988;6:93-101.

27. Cochrane bandbook for systematic reviews of interventions. Version 5.1.0. New York: John Wiley \& Sons; 2011

28. Waters E, de Silva-Sanigorski A, Hall BJ, et al. Interventions for preventing obesity in children. Cochrane Database Syst Rev 2011;(12):CD001871.

29. DerSimonian R, Laird N. Meta-analysis in clinical trials. Control Clin Trials 1986;7:177-88

30. Cohen, J. Statistical power analysis for the behavioral sciences. 2nd ed. Hillsdale (NJ): Erlbaum; 1988.

31. Chanoine JP, Hampl S, Jensen C, et al. Effect of orlistat on weight and body composition in obese adolescents: a randomized controlled trial. $7 A M A 2005$; 293:2873-83

32. Savoye M, Shaw M, Dziura J, et al. Effects of a weight management program on body composition and metabolic parameters in overweight children: a randomized controlled trial. 7AMA 2007;297:2697-704.

33. Golley RK, Magarey AM, Baur LA, et al. Twelve-month effectiveness of a parent-led, family-focused weight-management program for prepubertal children: a randomized, controlled trial. Pediatrics 2007;119:517-25.

34. McCallum Z, Wake M, Gerner B, et al. Outcome data from the LEAP (Live, Eat and Play) trial: a randomized controlled trial of a primary care intervention for childhood overweight/mild obesity. Int 7 Obes (Lond) 2007;31:630-6.

35. Saelens BE, Sallis JF, Wilfley DE, et al. Behavioral weight control for overweight adolescents initiated in primary care. Obes Res 2002;10:22-32.

36. Nemet D, Barkan S, Epstein Y, et al. Short- and long-term beneficial effects of a combined dietary-behavioral-physical activity intervention for the treatment of childhood obesity. Pediatrics 2005;115:e443-9.

37. Doyle AC, Goldschmidt A, Huang C, et al. Reduction of overweight and eating disorder symptoms via the Internet in adolescents: a randomized controlled trial. 7 Adolesc Health 2008;43:172-9.

38. Epstein LH, Roemmich JN, Robinson JL, et al. A randomized trial of the effects of reducing television viewing and computer use on body mass index in young children. Arch Pediatr Adolesc Med 2008;162:239-45.

39. Maahs D, de Serna DG, Kolotkin RL, et al. Randomized, double-blind, placebocontrolled trial of orlistat for weight loss in adolescents. Endocr Pract 2006; 12:18-28.

40. Bryant M, Farrin A, Christie D, et al. Results of a feasibility randomised controlled trial (RCT) for WATCH IT: a programme for obese children and adolescents. Clin Trials 2011;8:755-64

41. DeBar LL, Stevens VJ, Perrin N, et al. A primary care-based, multicomponent lifestyle intervention for overweight adolescent females. Pediatrics 2012;129: e611-20.

42. Croker H, Viner RM, Nicholls D, et al. Family-based behavioural treatment of childhood obesity in a UK National Health Service setting: randomized controlled trial. Int 7 Obes (Lond) 2012;36:16-26.

43. Coppins DF, Margetts BM, Fa JL, et al. Effectiveness of a multi-disciplinary family-based programme for treating childhood obesity (the Family Project). Eur 7 Clin Nutr 2011;65:903-9.

44. Wafa SW, Talib RA, Hamzaid NH, et al. Randomized controlled trial of a good practice approach to treatment of childhood obesity in Malaysia: Malaysian Childhood Obesity Treatment Trial (MASCOT). Int 7 Pediatr Obes 2011; 6:e62-9.

45. Taveras EM, Gortmaker SL, Hohman KH, et al. Randomized controlled trial to improve primary care to prevent and manage childhood obesity: the High Five for Kids study. Arch Pediatr Adolesc Med 2011;165:714-22.

46. Maddison R, Foley L, Ni MC, et al. Effects of active video games on body composition: a randomized controlled trial. Am 7 Clin Nutr 2011;94:156-63.

47. Waling $M$, Lind $\mathrm{T}$, Hernell $\mathrm{O}$, et al. A one-year intervention has modest effects on energy and macronutrient intakes of overweight and obese Swedish children. 7 Nutr 2010;140:1793-8.

48. Reinehr T, Schaefer A, Winkel K, et al. An effective lifestyle intervention in overweight children: findings from a randomized controlled trial on "Obeldicks light". Clin Nutr 2010;29:331-6.

49. Racine NM, Watras AC, Carrel AL, et al. Effect of conjugated linoleic acid on body fat accretion in overweight or obese children. Am 7 Clin Nutr 2010;91: 1157-64.

50. Wake M, Baur LA, Gerner B, et al. Outcomes and costs of primary care surveillance and intervention for overweight or obese children: the LEAP 2 randomised controlled trial. BMF 2009;339:b3308.

51. Weigel C, Kokocinski K, Lederer P, et al. Childhood obesity: concept, feasibility, and interim results of a local group-based, long-term treatment program. 7 Nutr Educ Behav 2008;40:369-73.

52. Bäcklund C, Sundelin G, Larsson C. Effects of a 2-year lifestyle intervention on physical activity in overweight and obese children. Adv Physiother 2011; 13:97-109.

53. Sacher PM, Kolotourou M, Chadwick PM, et al. Randomized controlled trial of the MEND program: A family-based community intervention for childhood obesity. Obesity (Silver Spring) 2010;18(Suppl 1):S62-8.

54. Janicke DM, Sallinen BJ, Perri MG, et al. Comparison of program costs for parent-only and family-based interventions for pediatric obesity in medically underserved rural settings. 7 Rural Health 2009;25:326-30.

55. Vos RC, Huisman SD, Houdijk ECAM, et al. The effect of family-based multidisciplinary cognitive behavioral treatment on health-related quality of life in childhood obesity. Qual Life Res 2012;21:1587-94.

56. Lisón JF, Real-Montes JM, Torró I, et al. Exercise intervention in childhood obesity: a randomized controlled trial comparing hospital-versus home-based groups. Acad Pediatr 2012;12:319-25.

57. Ebbeling CB, Feldman HA, Chomitz VR, et al. A randomized trial of sugarsweetened beverages and adolescent body weight. N Engl 7 Med 2012;367: 1407-16.

58. Toulabi T, Khosh Niyat NM, Amini F, et al. The influence of a behavior modification interventional program on body mass index in obese adolescents. 7 Formos Med Assoc 2012;111:153-9.

59. Wake M, Lycett K, Clifford SA, et al. Shared care obesity management in 3-10 year old children: 12 month outcomes of HopSCOTCH randomised trial. BM7 2013;346:f3092.

60. Lochrie AS, Wysocki T, Hossain J, et al. The effects of a family-based intervention (FBI) for overweight/obese children on health and psychological functioning. Clin Pract Pediatr Psychol. 2013;1:159-70.

61. O'Connor TM, Hilmers A, Watson K, et al. Feasibility of an obesity intervention for paediatric primary care targeting parenting and children: Helping HAND. Child Care Health Dev 2013;39:141-9.

62. Varni JW, Seid M, Kurtin PS. PedsQL 4.0: reliability and validity of the Pediatric Quality of Life Inventory version 4.0 generic core scales in healthy and patient populations. Med Care 2001;39:800-12.

63. Schmidt S, Debensason D, Muhlan H, et al. The DISABKIDS generic quality of life instrument showed cross-cultural validity 1. 7 Clin Epidemiol 2006; 59:587-98.

64. Clinical practice guidelines for the management of overweight and obesity in adults. Melbourne (Australia): National Health and Medical Research Council; 2013.

65. Wing RR, Lang W, Wadden TA, et al. Benefits of modest weight loss in improving cardiovascular risk factors in overweight and obese individuals with type 2 diabetes. Diabetes Care 2011;34:1481-6.

66. Kolotourou M, Radley D, Chadwick P, et al. Is BMI alone a sufficient outcome to evaluate interventions for child obesity? Child Obes 2013;9:350-6.

67. Look AHEAD Research Group. Eight-year weight losses with an intensive lifestyle intervention: the look AHEAD study. Obesity (Silver Spring) 2014;22:5-13.

Affiliations: McMaster Evidence Review and Synthesis Centre (Peirson, Fitzpatrick-Lewis, Warren, Usman Ali, Raina), McMaster University, Hamilton, Ont.; School of Nursing (Peirson, Fitzpatrick-Lewis, Warren), McMaster University, Hamilton, Ont.; Department of Pediatrics (Morrison), McMaster University, Hamilton, Ont.; Department of Clinical Epidemiology and Biostatistics (Usman Ali, Raina), McMaster University, Hamilton, Ont.

Acknowledgements: Parminder Raina holds a Tier 1 Canada Research Chair in Geroscience and the Raymond and Margaret Labarge Chair in Research and Knowledge Application for Optimal Aging. The authors thank Meghan Kenny, Mary Gauld and Eva Tsakonis for their contribution to the relevance and quality assessment, and the data extraction phases; Maureen Rice for the search; Sharon Peck-Reid for database management and report formatting; Sarah Connor Gorber and Amanda Shane (Public Health Agency of Canada) for contributing to the original protocol development and reviewing drafts of the technical report; and the Child Obesity Working Group of the Canadian Task Force on Preventive Health Care (Patricia Parkin, Maria Bacchus, Neil Bell, Paula Brauer and Elizabeth Shaw) for providing comments on the protocol and initial analyses.

Contributors: Leslea Peirson, Donna Fitzpatrick-Lewis, Katherine Morrison, Rachel Warren and Parminder Raina were responsible for the study's conceptualization, interpreting the data, and writing and revising the article. Leslea Peirson and Donna Fitzpatrick-Lewis were responsible for collecting the data and coordinating the project. Muhammad Usman Ali was responsible for analyzing the data, and writing and revising the article. All of the authors approved the final version of the manuscript submitted for publication and agree to act as guarantors of the work.

Funding: The Canadian Institutes of Health Research provided funding for this review but had no role in the design, analyses, interpretation or decision to submit the paper for publication.

Supplemental information: For reviewer comments and the original submission of this manuscript, please see www.cmajopen.ca/content/3/1 /E35/suppl/DC1 